\title{
JOSHA Print on Demand Service
}

\author{
Authors: Anusha Venkatraman \\ Submitted: $\quad$ 30. September 2017 \\ Published: $\quad$ 3. October 2017 \\ Volume: 4 \\ Issue: 4 \\ Affiliation: JOSHA \\ Keywords: $\quad$ Print on demand, Articles, Manuscripts, Theses, Archive \\ DOI: $\quad$ 10.17160/josha.4.4.331
}

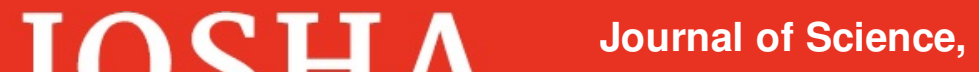 Humanities and Arts}




\section{Print on Demand Service}

26.09.17

With the September 2017 issue, JOSHA goes beyond being an electronic journal by introducing the new 'Print on demand' feature. This feature enables you to order a printed version of your favourite articles. The 'print on demand' feature is available for all individual articles with an option also to combine multiple articles from various issues and customize them into one. The printed version can be ordered by clicking on the 'Order Print on Demand' button below every published article. The print request can be completed by filling the form which appears when the 'Print on demand' button is clicked. The print service is offered by our printing partner Rombach Digital, Freiburg.

If you would like a printed version of your article that was published on JOSHA with a customised cover-page or simply a set of your favourite articles from the diverse topics available on JOSHA to be printed, then get your printed version now by clicking the 'Order Print on Demand' feature.

As a part of the new Demetrios Project, the textbooks that are published in various international languages could also be printed with a customised cover-page.

This service is also available for manuscripts, theses and any type of work submitted and deposit only in the JOSHA archive.

We wish you a joyous reading experience electronically and with your own printed version of the JOSHA articles! 